\title{
The Effect of Superparamagnetic Iron Oxide with iRGD Peptide on the Labeling of Pancreatic Cancer Cells In Vitro: A Preliminary Study
}

\author{
Hou Dong Zuo, ${ }^{1,2}$ Wei Wu Yao, ${ }^{2}$ Tian Wu Chen,, Jiang Zhu, ${ }^{1}$ Juan Juan Zhang, \\ Yu Pu, ${ }^{1}$ Gang Liu, ${ }^{1}$ and Xiao Ming Zhang ${ }^{1}$ \\ ${ }^{1}$ Sichuan Key Laboratory of Medical Imaging, Department of Radiology, Affiliated Hospital of North Sichuan Medical College, \\ Nanchong, Sichuan 637000, China \\ ${ }^{2}$ Department of Radiology, Shanghai Jiao Tong University Affiliated Sixth People’s Hospital, 600 Yishan Road, Shanghai 200233, China
}

Correspondence should be addressed to Xiao Ming Zhang; cjr.zhxm@vip.163.com

Received 10 February 2014; Revised 29 April 2014; Accepted 4 May 2014; Published 19 May 2014

Academic Editor: Yi-Xiang Wang

Copyright (c) 2014 Hou Dong Zuo et al. This is an open access article distributed under the Creative Commons Attribution License, which permits unrestricted use, distribution, and reproduction in any medium, provided the original work is properly cited.

\begin{abstract}
The iRGD peptide loaded with iron oxide nanoparticles for tumor targeting and tissue penetration was developed for targeted tumor therapy and ultrasensitive MR imaging. Binding of iRGD, a tumor homing peptide, is mediated by integrins, which are widely expressed on the surface of cells. Several types of small molecular drugs and nanoparticles can be transfected into cells with the help of iRGD peptide. Thus, we postulate that SPIO nanoparticles, which have good biocompatibility, can also be transfected into cells using iRGD. Despite the many kinds of cell labeling studies that have been performed with SPIO nanoparticles and RGD peptide or its analogues, only a few have applied SPIO nanoparticles with iRGD peptide in pancreatic cancer cells. This paper reports our preliminary findings regarding the effect of iRGD peptide (CRGDK/RGPD/EC) combined with SPIO on the labeling of pancreatic cancer cells. The results suggest that SPIO with iRGD peptide can enhance the positive labeling rate of cells and the uptake of SPIO. Optimal functionalization was achieved with the appropriate concentration or concentration range of SPIO and iRGD peptide. This study describes a simple and economical protocol to label panc-1 cells using SPIO in combination with iRGD peptide and may provide a useful method to improve the sensitivity of pancreatic cancer imaging.
\end{abstract}

\section{Introduction}

The development of metallic or inorganic nanoparticles for disease and cancer diagnostic imaging has progressed rapidly in recent years due to their unique physical characteristics, favorable biocompatibility, and specific targeting capabilities [1-5]. Among them, superparamagnetic iron oxide (SPIO) nanoparticles have a great potential for basic and clinical application due to their several advantages, such as guided transport or distribution under an external magnetic field in vivo and T2-type magnetic resonance imaging contrast enhancement $[3,4,6-10]$. In particular, negative contrast agents (e.g., SPIO) for molecular imaging that decrease the $\mathrm{T} 2$ and $\mathrm{T}^{*}$ relaxation times of tissues and provide higher sensitivity for MRI are advantageous because they have strong contrast effects, conveniently controlled magnetic characteristics, and improved biodegradability [11]. Cationic surfaces facilitate cellular internalization [12]. Currently, there is a huge research impetus in MR diagnostic imaging to develop hybrid SPIO nanoparticles integrated with multiple imaging detection components $[3,5,6,8,13]$. To date, SPIOs modified or coated with dextran, polystyrene, polyethylene glycol (PEG), and polylysine (PLL) have been studied and applied [11, 13-15].

Integrins, which consist of an $\alpha$ and a $\beta$ subunit, are a family of heterodimeric glycoprotein receptors on the cell surface which mediate and diversify biological communication involving cell adhesion and signal transduction [16]. Currently, 24 integrin subtypes have been reported $[17,18]$, while $\alpha \mathrm{v} \beta 3$ integrin that is overexpressed on tumor cells is one of the most prominent receptors involved in tumor growth, invasiveness, and metastasis [16, 19-22]. The $\alpha \mathrm{v}$ 
integrins and neuropilin-1 are expressed on pancreatic cancer cells, including the panc-1 cell line [23-29]. In addition, $\alpha \mathrm{v} \beta 3$ integrin can be targeted by peptides with a short amino acid sequence containing Arg-Gly-Asp (RGD) [3, 22, 30-32]. The iRGD (CRGDK/RGPD/EC) peptide is a newly identified type of tumor-penetrating peptide, which was discovered by phage display. The peptide can increase the permeability of tumor cells, mediate cellular internalization and extravasation, and enhance deep tissue penetration to improve the imaging sensitivity and therapeutic efficacy mediated by integrins and neuropilin-1 (NRP-1) receptors [3, 23, 30]. The iRGD peptide plays a part in targeting tumor cells using a similar procedure to conventional RGD peptides $[3,30]$. Recently, the application of RGD peptide with SPIO has been an active focus of research. Zhang et al. [31] evaluated RGD-USPIO uptake in cultured human umbilical vein endothelial cells (HUVECs) in vitro by MRI.

Here, we propose and investigate a new strategy for integrin targeting and tumor diagnostic imaging based on iRGD peptide. We aim to (1) study the effect of SPIO with iRGD peptide on the labeling of pancreatic cancer cells in vitro and (2) find a new and useful modality for pancreatic cancer diagnostic imaging. To our knowledge, there have been no studies investigating the biophysical properties of SPIO with iRGD peptide for cellular MR imaging. Therefore, this study is novel, and previous studies suggest that it is feasible. The intracellular uptake of Fe, the viability of labeled cells, and their MRI signal intensity (SI) changes were assessed. The results suggest that our modality may be useful for alternative cell labeling and pancreatic cancer diagnostic imaging.

\section{Materials and Methods}

2.1. Chemicals, Reagents, and Experimental Instruments. The human pancreatic cancer cell line (panc-1) was provided by Sichuan University. The following other materials and instruments were used: iRGD peptide, SPIO (Resovist, SHU555A, SCHERING Company, Germany), polylysine, fetal bovine serum, RPMI-1640 solution, trypsin, a 3.0 T MR scanner (Discovery MR 750; GE Medical Systems, Milwaukee, WI), an inverted microscope (TS100-F), an oven (DGX-9143), and an atomic absorption spectrophotometer (AAS, SpectrAA 220FS, $12^{\circ} \mathrm{C}, 63 \%$ humidity).

2.2. The Concentration of Reagents and Solutions. The nutrient solution consisted of 85\% RPMI-1640 solution and 15\% fetal bovine serum. SPIO mixed solution had $840 \mu \mathrm{g}$ iron ion per $\mathrm{mL}$. The following solutions were used: $10 \%$ iRGD peptide solution, $0.5 \%$ neutral red solution, PBS buffer solution $(0.1 \mathrm{~mol} / \mathrm{L}, \mathrm{pH} 7.4)$, and $0.25 \%$ trypsin. The iron ion concentration of SPIO and the PLL mixture solution was $840 \mu \mathrm{g}$ per mL. Perl's staining solution was composed of $2 \%$ potassium ferrocyanide solution and 3\% diluted hydrochloric acid mixed in an equal volume.

2.3. Cell Culture and Treatment. The human pancreatic cancer cells $\left(1 \times 10^{6}\right.$ cells/well, $9.6 \mathrm{~cm}^{2}$ per well $)$ were cultured

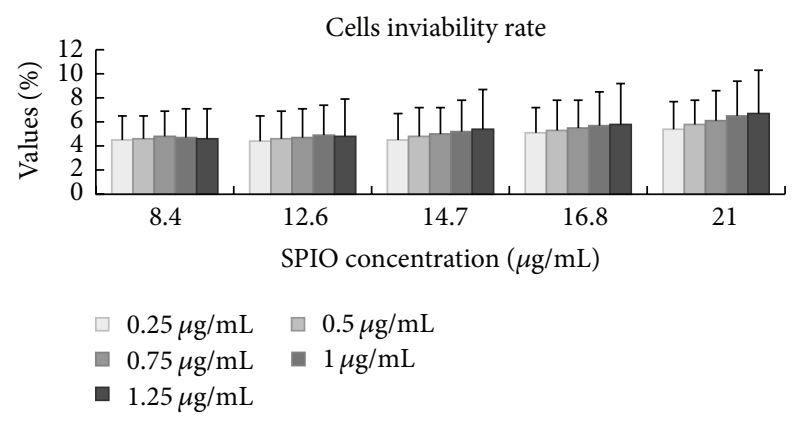

FIGURE 1: The rate of nonviable cells for different SPIO and iRGD peptide concentrations. As shown in the graph, trypan blue staining demonstrated that there was not a remarkable reduction in the viability of panc- 1 cells after incubation with increasing concentrations of SPIO and iRGD peptide.

for 24 hours. Then, the cells were washed with phosphate buffered saline (PBS) three times. Afterwards, the SPIO and iRGD peptide solutions were coadministered. The total solution volume was $2 \mathrm{~mL}$ per well. The iron ion concentrations were $8.4 \mu \mathrm{g} / \mathrm{mL}, 12.6 \mu \mathrm{g} / \mathrm{mL}, 14.7 \mu \mathrm{g} / \mathrm{mL}, 16.8 \mu \mathrm{g} / \mathrm{mL}$, and $21 \mu \mathrm{g} / \mathrm{mL}$. The iRGD peptide solution concentrations added were $0.25 \mu \mathrm{g} / \mathrm{mL}, 0.5 \mu \mathrm{g} / \mathrm{mL}, 0.75 \mu \mathrm{g} / \mathrm{mL}, 1.0 \mu \mathrm{g} / \mathrm{mL}$, and $1.25 \mu \mathrm{g} / \mathrm{mL}$, respectively. Considering the $8.4 \mu \mathrm{g} / \mathrm{mL}$ concentration as an example, $1980 \mu \mathrm{L}, 1980 \mu \mathrm{L}, 1975 \mu \mathrm{L}, 1970$ $\mu \mathrm{L}, 1965 \mu \mathrm{L}, 1960 \mu \mathrm{L}$, and $1955 \mu \mathrm{L}$ of nutrient culture were first added to each of the 6 wells. Next, $20 \mu \mathrm{L}$ SPIO solution was added to each well followed by $0 \mu \mathrm{L}, 0 \mu \mathrm{L}, 5 \mu \mathrm{L}, 10 \mu \mathrm{L}$, $15 \mu \mathrm{L}, 20 \mu \mathrm{L}$, and $25 \mu \mathrm{L}$ iRGD peptide solution, respectively. As control, SPIO-PLL was added in another well with each SPIO concentration series. Next, the cells were incubated for 24 hours. After incubation, the culture medium was removed. The adherent cells were washed with PBS three times, trypsinized, washed with PBS, and centrifuged for 5 minutes at $1000 \mathrm{rpm}$. The total number of cells $\left(1 \times 10^{6}\right)$ was determined using a counting chamber. Then, the cells were embedded in agar (1\%) at room temperature for MRI examination.

2.4. Cell Viability. The viability of the cells cultured under different conditions was evaluated with $0.4 \%$ trypan blue dye solution. The percentage of nonviable or dead cells was determined by counting trypan blue-positive and trypan blue-negative cells in a counting chamber. The nonviable rate was calculated. The group with the highest concentration of iRGD peptide within each iron concentration series was analyzed.

2.5. MR Sequence, Parameters, and Measurement. MR T2 relaxometry of panc-1 cells in agar was performed using a fast recovery fast spin echo T2 weighted (FRFSE-T2W) sequence with a 32-channel head coil in a $3.0 \mathrm{~T}$ MR scanner (slice thickness: $2 \mathrm{~mm}$; interslice space: $0-0.5 \mathrm{~mm}$; TR: $2800.0 \mathrm{~ms}$; TE: $90.3 \mathrm{~ms}$; DFOV: $18.0 \times 18.0 \mathrm{~cm}$; reconstruction matrix: $512 \times 256)$. All the original images were transferred to an ADW4.4 workstation, and the best images were selected. 


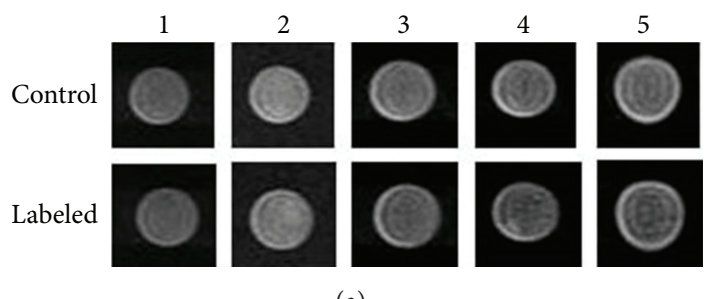

(a)
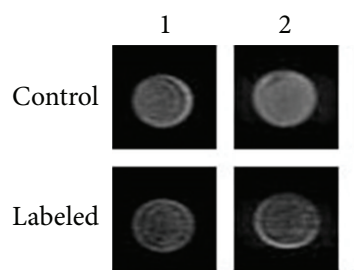

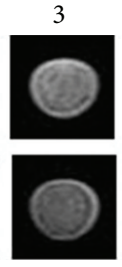

(c)
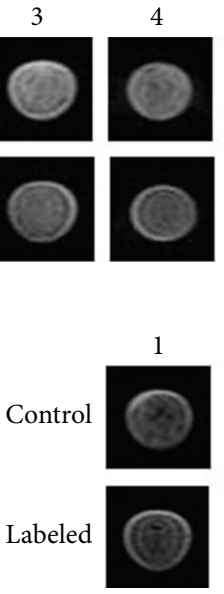
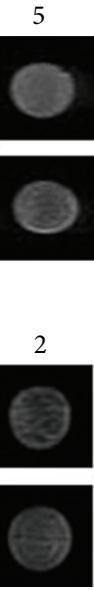
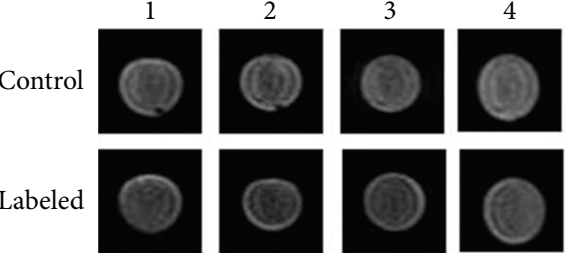

(b)
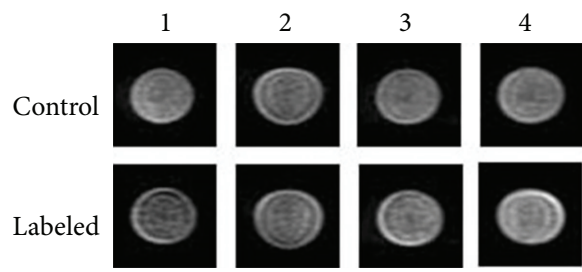

(d)
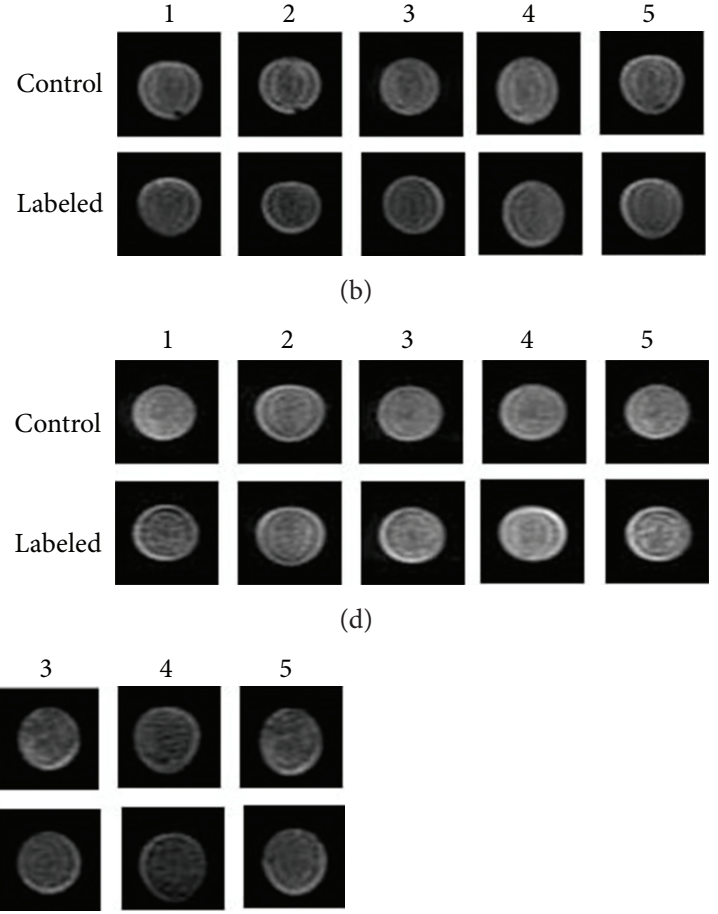

(e)

FIGURE 2: MR images of labeled cells in agar $\left(1 \times 10^{6}\right.$ cells) acquired using T2-weighted imaging with the FRFSE sequence. (a)-(e) indicate the iron ion concentration (from 8.4 to $21 \mu \mathrm{g} / \mathrm{mL}$, resp.). The numbers $1-5$ represent the iRGD peptide concentration (from 0.25 to $1.25 \mu \mathrm{g} / \mathrm{mL}$, resp.).

Identification of $25 \mathrm{~mm}^{2}$ regions of interest (ROI) was performed in triplicate, and the mean values were adopted. The signal intensity reduction value $(\Delta S)$ of every sample (including the SPIO-PLL group) relative to the control group was measured within the same SPIO concentration. The signal intensity changes $\left(\Delta S^{\prime}\right)$ of every sample (including the SPIO control group) were also measured relative to the PBS blank group with the same SPIO concentration to analyze the appropriate concentration of iRGD to SPIO concentration. All the data were processed and measured on the ADW4.4 workstation.

2.6. Prussian Blue Staining. For Prussian blue staining, the cells were cultivated for 24 hours in 6-well plates on glass coverslips $\left(1 \times 10^{6}\right.$ cells $)$. After incubation, the labeled panc1 cells were washed three times with PBS and subsequently fixed with $4 \%$ paraformaldehyde for 40 to 60 minutes. Then, the fixed cells were incubated with Perl's dye for 30 minutes and counterstained with $0.5 \%$ neutral red solution for 1 minute.

\subsection{Inverted Microscope Observation and Transmission Elec-} tron Microscopy. The cells on glass coverslips were placed on slides, fixed, and then observed with an inverted microscope. The cells were routinely observed using 10x, 20x, and 40x magnification views. Photos were taken at random sites under 40x magnification. The positive labeled cells were counted under 4 magnification views (40x and 20x) randomly, and the positive labeled rate was calculated (positive labeled cell counts/total cell counts $\times 100 \%)$. The cells cultured with $12.6 \mu \mathrm{g} / \mathrm{mL}$ iron ion and $1 \mu \mathrm{g} / \mathrm{mL}$ iRGD peptide were selected for observation with a transmission electron microscope.

2.8. The Quantification of Iron Cell Content. After MRI scanning, the group with the best concentrations of SPIO and iRGD peptide was selected and the samples were treated with $15 \mathrm{~mL}$ aqua regia $\left(V_{\mathrm{HCL}}: V_{\mathrm{HNO}_{3}}=3: 1\right)$ for the determination of the iron content by AAS.

2.9. Statistical Analysis. The continuous data were expressed as mean \pm standard deviation (SD). Statistical analysis was conducted using a nonparametric Wilcoxon rank sum test. A 2-independent samples test was performed in the analysis of $\Delta S^{\prime}$ and cell viability. Statistical analysis was conducted with the SPSS16.0 software package for Windows (SPSS Institute, Chicago, IL, USA). An $\alpha$ level of 0.05 was used.

\section{Results}

3.1. Evaluation of Cell Viability. Trypan blue staining did not demonstrate reduced viability of panc-1 cells after incubation with increasing concentrations of SPIO and iRGD peptide, including the SPIO and SPIO-PLL control groups. There were no significant differences among the samples. For example, for the highest concentration of iron ions $(21 \mu \mathrm{g} / \mathrm{mL})$ in this study, the percentages of nonviable cells for the different 


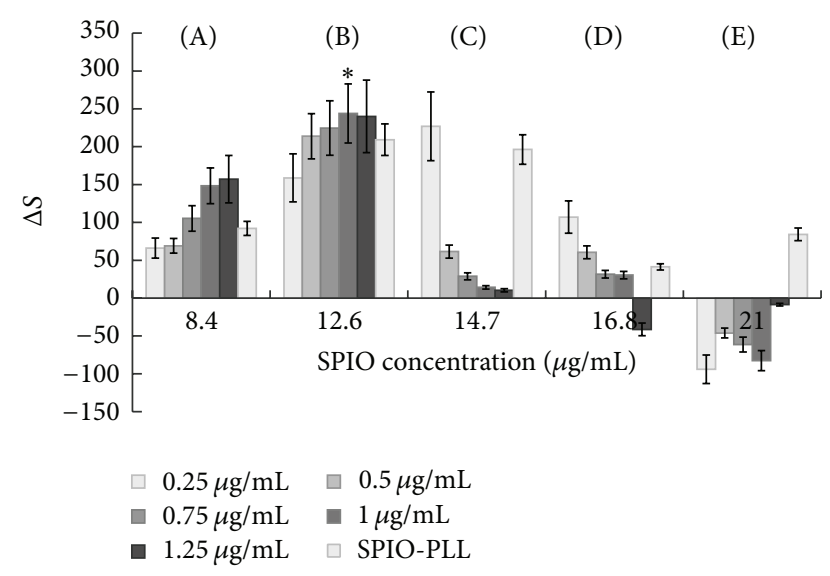

FIGURE 3: The evaluation of the mean signal reduction $(\Delta S)$ for different iron ion concentrations. (A)-(E) indicate $8.4-21 \mu \mathrm{g} / \mathrm{mL}$ iron ion concentration. The SPIO-PLL group served as the control group. ${ }^{*}$ The highest $\Delta S$ value (the best concentration match of iron ions and iRGD peptide).

concentrations of the iRGD peptide samples were $5.4 \pm 2.5 \%$, $5.8 \pm 3.1 \%, 6.1 \pm 3.3 \%, 6.5 \pm 3.4 \%$, and $6.7 \pm 3.6 \%$, respectively. These values did not differ significantly from each other (Figure 1).

3.2. In Vitro MRI Evaluation of T2-W. When the concentration of iron was $8.4 \mu \mathrm{g} / \mathrm{mL}$, the signal intensity of the labeled cell samples decreased gradually with the increase in iRGD peptide concentration (Figures 2(a) and 3). The mean $\Delta S$ increased correspondingly. When the concentration reached $12.6 \mu \mathrm{g} / \mathrm{mL}$, the signal intensity first decreased and then increased with increasing concentrations of iRGD peptide. Therefore, the mean $\Delta S$ first increased and then decreased. The $\Delta S$ was the highest $(243.89 \pm 89.1)$ with $1 \mu \mathrm{g} / \mathrm{mL}$ of iRGD peptide (Figures 2(b) and 3). When the iron concentrations were $14.7 \mu \mathrm{g} / \mathrm{mL}$ and $16.8 \mu \mathrm{g} / \mathrm{mL}$, the signal intensity was enhanced with increasing concentration of iRGD. Consequently, the mean $\Delta S$ reduced gradually (Figures $2(\mathrm{c})-2(\mathrm{~d})$ and 3). However, when the iron concentration was $21 \mu \mathrm{g} / \mathrm{mL}$, the signal intensities for different iRGD concentrations differed from each other and were higher than those of the control group (Figures 2(e) and 3). The mean $\Delta S$ of the SPIO-PLL group was slightly lower than that of groups with the appropriate iRGD peptide concentration and iron concentrations of 12.6 and $14.7 \mu \mathrm{g} / \mathrm{mL}$ (Figure 3).

We also determined the appropriate concentration of iRGD peptide within the same series of iron ion concentrations. No significant difference in the mean $\Delta S^{\prime}$ was found between the treatment group and control groups $(P>0.05)$ for the $8.4 \mu \mathrm{g} / \mathrm{mL}$ concentration of iron ions. However, when the concentration of iron ions was $12.6 \mu \mathrm{g} / \mathrm{mL}$, there was a significant difference between the treatment and control groups $(P<0.05)$. Only one group $(0.25 \mu \mathrm{g} / \mathrm{mL}$ iRGD) differed from the control group at the $14.7 \mu \mathrm{g} / \mathrm{mL}$ concentration of iron ions. However, no significant difference was found for the other two iron ion concentrations. Therefore, our results suggest that the appropriate concentration of iRGD

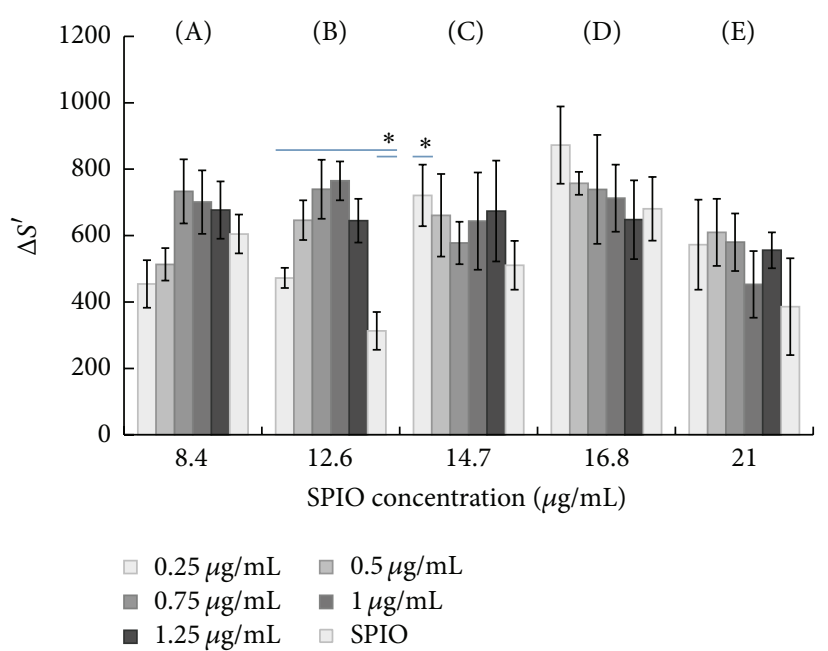

FIGURE 4: The evaluation of the mean signal reduction values $\left(\Delta S^{\prime}\right)$ for different iron concentrations. For the iron concentration of $12.6 \mu \mathrm{g} / \mathrm{mL}$, a significant difference was found between the treatment and control groups $(P<0.05)$. For the iron concentration of $14.7 \mu \mathrm{g} / \mathrm{mL}$, a significant difference was only found between $0.25 \mu \mathrm{g} / \mathrm{mL}$ iRGD and the control group. (A)-(E) indicate 8.4$21 \mu \mathrm{g} / \mathrm{mL}$ iron ion concentration. The SPIO group served as the control group. ${ }^{*} P<0.05$.

peptide was $0.25-1.25 \mu \mathrm{g} / \mathrm{mL}$ for the $12.6 \mu \mathrm{g} / \mathrm{mL}$ iron ion concentration and $0.25 \mu \mathrm{g} / \mathrm{mL}$ for the $14.7 \mu \mathrm{g} / \mathrm{mL}$ of iron ion concentration (Figure 4).

3.3. Microscope Observation, Characteristics of Prussian Blue Staining, and Transmission Electron Microscopy. Cells treated with $12.6 \mu \mathrm{g} / \mathrm{mL}$ concentration of SPIO and a range of iRGD peptide concentrations were selected for observation. The labeled cells were diamond or oval in shape under microscopic observation when treated with iron oxide and the range of iRGD. When the cells were incubated with $1 \mu \mathrm{g} / \mathrm{mL}$ iRGD at an iron concentration of $12.6 \mu \mathrm{g} / \mathrm{mL}$, the positive labeling rate of the treatment group was enhanced relative to the control group (Figure 6). The morphology of the cells was good. Speckled, granular, and patchy bluestained particles were observed in the cytoplasm, cell nucleus, and cell membrane (Figure 5). The granules were mostly in the cytoplasm around the nuclei. The distribution of the intracellular $\mathrm{Fe}$ granules observed under transmission electron microscope is shown in Figures 5(e)-5(f).

The positive labeling rate after treatment was not different than that of the control group with $12.6 \mu \mathrm{g} / \mathrm{mL}$ SPIO (Figure 6). The iron content determination was confirmed by AAS analysis. The mean iron content ( $\mathrm{pg} / \mathrm{cell})$ of each treatment sample with increasing concentration of iRGD peptide was $2.42 \mathrm{pg}, 5.61 \mathrm{pg}, 8.12 \mathrm{pg}, 10.74 \mathrm{pg}$, and $13.20 \mathrm{pg}$, respectively, which was higher than that of the control sample $(0.94 \mathrm{pg} / \mathrm{cell})$.

\section{Discussion}

In the present study, the ability of SPIO combined with iRGD peptide to specifically bind to the $\alpha \mathrm{v} \beta 3$ integrin on 


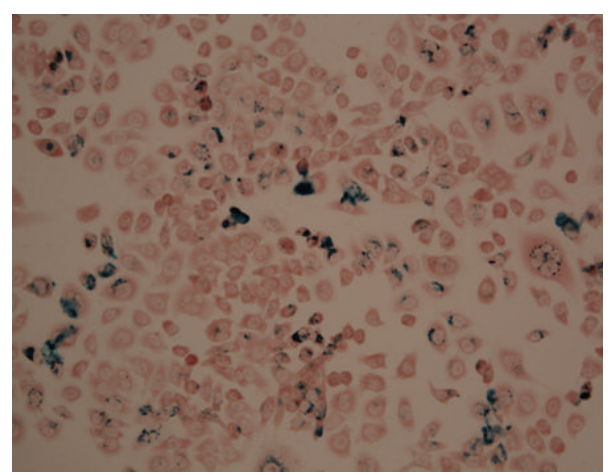

(a)

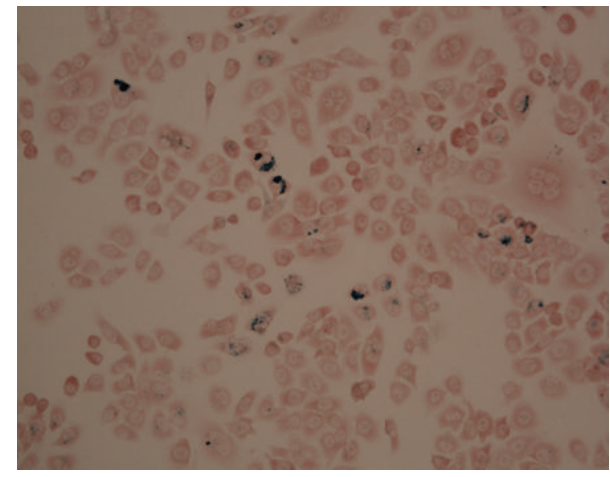

(c)

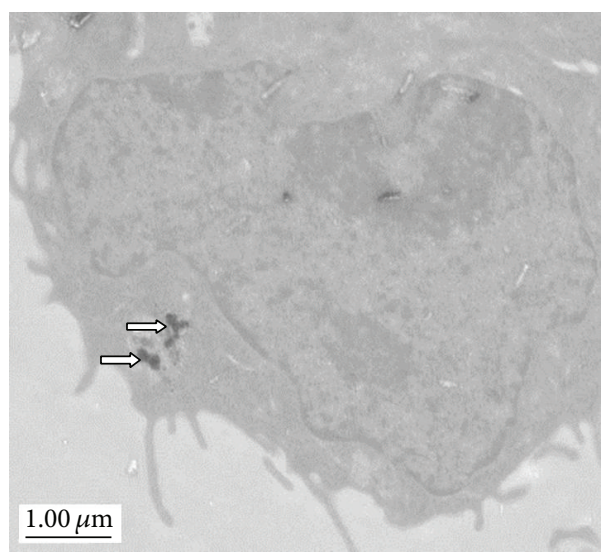

(e)

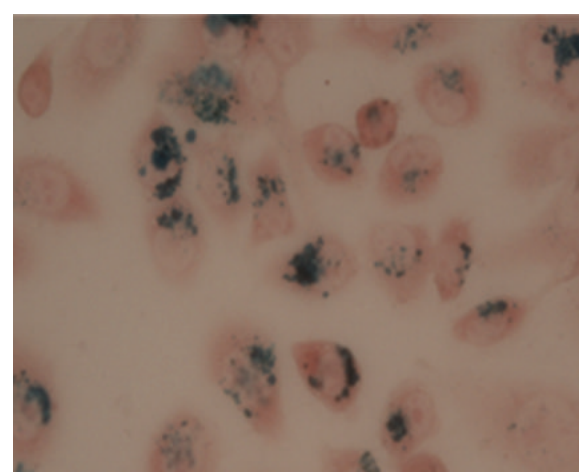

(b)

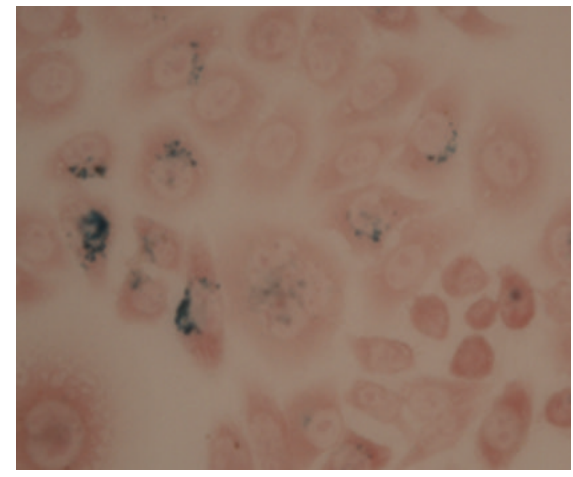

(d)

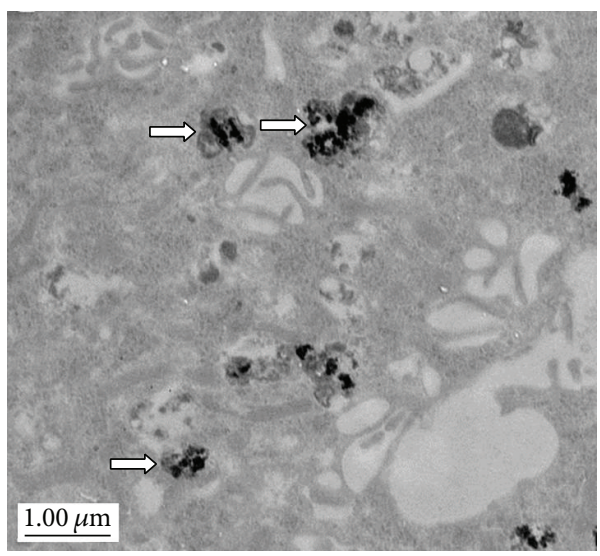

(f)

FIgURE 5: Prussian blue-stained and neutral red solution-counterstained panc-1 cells incubated with SPIO. (a), (b) The cells were incubated with $1 \mu \mathrm{g} / \mathrm{mL}$ iRGD at an iron concentration of $12.6 \mu \mathrm{g} / \mathrm{mL}((\mathrm{a}): 20 \mathrm{x}$ and (b): 40x). The cells of the control groups were incubated with SPIO without iRGD ((c): 20x and (d): 40x). Higher uptake of SPIO (blue-stained granules) with iRGD peptide compared with SPIO is clearly demonstrated (c, d). Electron microscopy of cells labeled with SPIO nanoparticles (e) and SPIO nanoparticles with iRGD peptide (f) (arrows).

tumor cells was investigated in vitro. In contrast to previous studies of molecular MR probes coated or modified with dextran or peptides $[33,34]$, we explored a novel method of coadministration of SPIO and iRGD peptide that may be useful in the enhancement of tumor imaging. Our results suggest that this method was also effective in labeling cells for MR molecular imaging.

Imaging of pancreatic cancer cells using MRI provides good spatial resolution, resulting in exquisite dynamic information and anatomical contrast, while the kinetics of SPIO distribution in tumor xenografts can be monitored with noninvasive modalities $[1,35]$. In recent years, T2 and $\mathrm{T} 2{ }^{*}$ sequence-mediated MR imaging with SPIO nanoparticles has become a favorable technique that may be available in the clinic. SPIO is a kind of negative contrast that can reduce T2 and T2* values and has increased sensitivity for MRI due to susceptibility effects [31]. Therefore, intracellular iron has strong $\mathrm{T} 2$ and $\mathrm{T} 2{ }^{*}$ effects, and the high reduction in signal is related to the increase in iron oxide uptake by the cells. Human pancreatic cancer cells can be labeled with SPIO and 


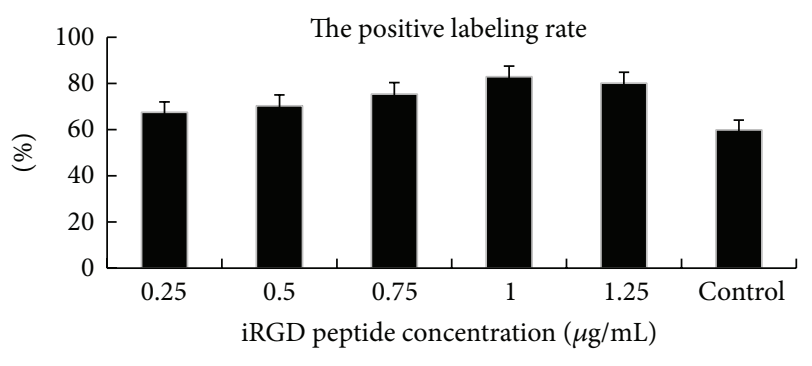

- $12.6 \mu \mathrm{g} / \mathrm{mL}$

FIgURE 6: The evaluation of the positive labeled cells. The positive labeling rate of the control was lower than that of the iRGD treatment groups. Control denotes the control group (SPIO). The concentration of SPIO was $12.6 \mu \mathrm{g} / \mathrm{mL}$.

induce tumor xenografts in nude mice after injection. Our results have demonstrated the efficient nanoparticle uptake capabilities of cells.

To optimize MR imaging in vitro and maximize the reliability of the results, it is important that (i) the labeling is reproducible, (ii) the function and viability of labeled cells are retained, and (iii) the process does not affect the target cells [36]. Therefore, we analyzed the cell viability at the beginning of the study through trypan blue staining with different concentrations of iron oxide and iRGD peptide and demonstrated the feasibility of our method.

Several kinds of amino acids have been used to enhance the uptake of SPIO nanoparticles, and the use of polylysine (PLL) has frequently proven to be feasible and efficient [1]. However, Kobukai et al. demonstrated that the use of PLL may be a double-edged sword; the compound can be either safe or toxic depending on the concentration used [37]. Another group suggested that PLL may trigger an inflammatory response by releasing the proinflammatory cytokine, tumor necrosis factor (TNF) [38].

Here, we investigated a new peptide (iRGD peptide) that has a similar function to PLL. The cyclic peptides containing the RGD sequence home to the $\alpha \mathrm{v} \beta 3$ integrin specifically and have been applied widely to integrin targeting on cancer pathology, molecular imaging, and drug delivery [3, 30, 31, 34]. This kind of disulfide-based cyclic RGD peptide, called iRGD (CRGDK/RGPD/EC), can interact with both integrin and neuropilin-1 receptors to mediate cellular internalization to improve imaging sensitivity [3]. Sugahara et al. [30]. reported that iron-oxide nanoworms (16) and T7 phage extravasated and have enhanced accumulation in tumor cells upon iRGD coadministration. Therefore, we combined the tumor-penetrating peptide and contrast agents in our study. In addition, this method may also have the following additional advantages: (i) the combination does not involve SPIO surface modification, which may impair the biological characteristics or good compatibility of the particles, and (ii) the quantity or concentration of materials can easily be adjusted during the course of experiments.

In the present study, five different iron concentrations of SPIO were selected according to our previous preliminary experiment. Thorek and Tsourkas reported the appropriate iron oxide concentration as less than $50 \mu \mathrm{g} / \mathrm{mL}$ in nonphagocytic cells [39]. Kobukai et al. reported that there were no registered dead dendritic cells treated with SPIO nanoparticles and PLL up to the $20 \mu \mathrm{g} / \mathrm{mL}$ concentration threshold. Meanwhile, SPIO nanoparticles neither were toxic nor reduced the viability of the cells [37]. In our previous study, we found the appropriate iron concentration range for labeling panc- 1 cells to be $21-42 \mu \mathrm{g} / \mathrm{mL}$. A similar result was reported by Boutry et al. Therefore, in the present study, a concentration lower than $21 \mu \mathrm{g} / \mathrm{mL}$ was selected and ensured [40].

After 24 hours of incubation, differences in the SPIO uptake were found between the treatment and control groups. The control group had less pronounced signal and intracellular iron oxide content. However, with high iron concentrations $(14.7-21 \mu \mathrm{g} / \mathrm{mL})$, the iRGD peptide effect reduced and was even inverse. This may be explained by the fact that the $\alpha \mathrm{v} \beta 3$ integrins were saturated or phagocytosis became the predominant mechanism of nanoparticle uptake [31]. Another possible reason is that the saturation of $\alpha \mathrm{v} \beta 3$ integrins may inhibit phagocytosis in the presence of high iron concentrations. Our study results show that the uptake and specific binding of our iRGD and SPIO to panc-1 cells in the treatment group were higher than those in the control group, which pointed to a receptor-mediated endocytosis mechanism with the appropriate iron and iRGD exposure. These findings were confirmed by light microscopy, transmission electron microscopy (TEM), and AAS.

A few points must be addressed for better understanding of the results and for improved design of more effective molecular labeling strategies. First, the present results suggest that a small quantity of iRGD peptides can optimally label cells in vitro. The longitudinal tracking of pancreatic cancer cells and further investigation in vivo using MR will be more challenging than in vitro studies. However, this study can be deemed a step towards in vivo tracking of pancreatic cancer cells with iRGD peptide and SPIO. Further investigation in animal tumor models remains a key goal of our ongoing studies.

In conclusion, our findings demonstrate that iRGD peptide affects the uptake of iron oxide during labeling of panc1 cells. An appropriate iRGD peptide concentration can enhance the uptake of intracellular iron. The importance of this study lies in its description of a new potential strategy for pancreatic cancer imaging.

\section{Conflict of Interests}

The authors declare that there is no conflict of interests regarding the publication of this paper.

\section{Authors' Contribution}

Hou Dong Zuo and Tian Wu Chen contributed equally to this work.

\section{Acknowledgment}

This work was supported by the National Nature Science Foundation of China Grant no. 81271643. 


\section{References}

[1] S. Toki, R. A. Omary, K. Wilson et al., "A comprehensive analysis of transfection-assisted delivery of iron oxide nanoparticles to dendritic cells," Nanomedicine, vol. 9, no. 8, pp. 1235-1244, 2013.

[2] E. S. Lee, C. Lim, H. T. Song et al., "A nanosized delivery system of superparamagnetic iron oxide for tumor MR imaging," International Journal of Pharmaceutics, vol. 439, no. 1-2, pp. 342348, 2012.

[3] K. N. Sugahara, T. Teesalu, P. P. Karmali et al., "Tissuepenetrating delivery of compounds and nanoparticles into tumors," Cancer Cell, vol. 16, no. 6, pp. 510-520, 2009.

[4] Z. Wang and A. Cuschieri, "Tumour cell labelling by magnetic nanoparticles with determination of intracellular iron content and spatial distribution of the intracellular iron," International Journal of Molecular Sciences, vol. 14, no. 5, pp. 9111-9125, 2013.

[5] X. Yang, J. J. Grailer, I. J. Rowland et al., "Multifunctional SPIO/DOX-loaded wormlike polymer vesicles for cancer therapy and MR imaging," Biomaterials, vol. 31, no. 34, pp. 90659073, 2010.

[6] H. Baraki, N. Zinne, D. Wedekind et al., "Magnetic resonance imaging of soft tissue infection with iron oxide labeled granulocytes in a rat model," PLoS ONE, vol. 7, no. 12, Article ID e51770, 2012.

[7] E. A. Neuwelt, P. Várallyay, A. G. Bagó et al., "Imaging of iron oxide nanoparticles by MR and light microscopy in patients with malignant brain tumours," Neuropathology and Applied Neurobiology, vol. 30, no. 5, pp. 456-471, 2004.

[8] J. Hu, Y. Qian, X. Wang et al., "Drug-loaded and superparamagnetic iron oxide nanoparticle surface-embedded amphiphilic block copolymer micelles for integrated chemotherapeutic drug delivery and MR imaging," Langmuir, vol. 28, no. 4, pp. 20732082, 2012.

[9] A. S. Arbab, W. Liu, and J. A. Frank, "Cellular magnetic resonance imaging: current status and future prospects," Expert Review of Medical Devices, vol. 3, no. 4, pp. 427-439, 2006.

[10] M. Modo, M. Hoehn, and J. W. M. Bulte, "Cellular MR imaging," Molecular Imaging, vol. 4, no. 3, pp. 143-164, 2005.

[11] D. Kim, K. S. Hong, and J. Song, "The present status of cell tracking methods in animal models using magnetic resonance imaging technology," Molecules and Cells, vol. 23, no. 2, pp. 132137, 2007.

[12] A. Petri-Fink and H. Hofmann, "Superparamagnetic iron oxide nanoparticles (SPIONs): from synthesis to in vivo studies-a summary of the synthesis, characterization, in vitro, and in vivo investigations of SPIONs with particular focus on surface and colloidal properties," IEEE Transactions on Nanobioscience, vol. 6, no. 4, pp. 289-297, 2007.

[13] H. Kojima, Y. Mukai, M. Yoshikawa et al., "Simple PEG conjugation of SPIO via an Au-S bond improves its tumor targeting potency as a novel MR tumor imaging agent," Bioconjugate Chemistry, vol. 21, no. 6, pp. 1026-1031, 2010.

[14] X. Wang, F. Wei, A. Liu et al., "Cancer stem cell labeling using poly(L-lysine)-modified iron oxide nanoparticles," Biomaterials, vol. 33, no. 14, pp. 3719-3732, 2012.

[15] T. Bach-Gansmo, "Ferrimagnetic susceptibility contrast agents," Acta Radiologica, vol. 387, pp. 1-30, 1993.

[16] R. O. Hynes, "Integrins: versatility, modulation, and signaling in cell adhesion," Cell, vol. 69, no. 1, pp. 11-25, 1992.

[17] P. C. Brooks, R. A. F. Clark, and D. A. Cheresh, "Requirement of vascular integrin $\alpha(\mathrm{v}) \beta 3$ for angiogenesis," Science, vol. 264, no. 5158, pp. 569-571, 1994.
[18] M. Kim, C. V. Carman, and T. A. Springer, "Bidirectional transmembrane signaling by cytoplasmic domain separation in integrins," Science, vol. 301, no. 5640, pp. 1720-1725, 2003.

[19] H. Jin and J. Varner, "Integrins: roles in cancer development and as treatment targets," British Journal of Cancer, vol. 90, no. 3, pp. 561-565, 2004.

[20] J. A. Varner and D. A. Cheresh, "Tumor angiogenesis and the role of vascular cell integrin alphavbeta3," Important Advances in Oncology, pp. 69-87, 1996.

[21] C. C. Kumar, "Integrin $\alpha \mathrm{v} \beta 3$ as a therapeutic target for blocking tumor-induced angiogenesis," Current Drug Targets, vol. 4, no. 2, pp. 123-131, 2003.

[22] M. Friedlander, C. L. Theesfeld, M. Sugita et al., "Involvement of integrins alpha v beta 3 and alpha v beta 5 in ocular neovascular diseases," Proceedings of the National Academy of Sciences of the United States of America, vol. 93, no. 18, pp. 9764-9769, 1996.

[23] Y. Akashi, T. Oda, Y. Ohara et al., "Anticancer effects of gemcitabine are enhanced by co-administered iRGD peptide in murine pancreatic cancer models that overexpressed neuropilin-1," British Journal of Cancer, vol. 110, no. 6, pp. 14811487, 2014.

[24] M. Trajkovic-Arsic, P. Mohajerani, A. Sarantopoulos et al., "Multimodal molecular imaging of integrin $\alpha \mathrm{v} \beta 3$ for in vivo detection of pancreatic cancer," Journal of Nuclear Medicine, vol. 55, no. 3, pp. 446-451, 2014.

[25] S. Ji, J. Xu, B. Zhang et al., "RGD-conjugated albumin nanoparticles as a novel delivery vehicle in pancreatic cancer therapy," Cancer Biology and Therapy, vol. 13, no. 4, pp. 206-215, 2012.

[26] H. Sawai, Y. Okada, H. Funahashi et al., "Basement membrane proteins play an important role in the invasive processes of human pancreatic cancer cells," Journal of Surgical Research, vol. 144, no. 1, pp. 117-123, 2008.

[27] R. J. Weinel, A. Rosendahl, K. Neumann et al., "Expression and function of VLA- $\alpha 2,-\alpha 3,-\alpha 5$ and $-\alpha 6$-integrin receptors in pancreatic carcinoma," International Journal of Cancer, vol. 52, no. 5, pp. 827-833, 1992.

[28] S. E. Holloway, A. W. Beck, L. Girard et al., "Increased expression of Cyr61 (CCN1) identified in peritoneal metastases from human pancreatic cancer," Journal of the American College of Surgeons, vol. 200, no. 3, pp. 371-377, 2005.

[29] R. Hosotani, M. Kawaguchi, T. Masui et al., "Expression of integrin alphaVbeta3 in pancreatic carcinoma: relation to MMP-2 activation and lymph node metastasis," Pancreas, vol. 25, no. 2, pp. e30-e35, 2002.

[30] K. N. Sugahara, T. Teesalu, P. Prakash Karmali et al., "Coadministration of a tumor-penetrating peptide enhances the efficacy of cancer drugs," Science, vol. 328, no. 5981, pp. 1031-1035, 2010.

[31] C. Zhang, M. Jugold, E. C. Woenne et al., "Specific targeting of tumor angiogenesis by RGD-conjugated ultrasmall superparamagnetic iron oxide particles using a clinical 1.5-T magnetic resonance scanner," Cancer Research, vol. 67, no. 4, pp. 15551562, 2007.

[32] M. A. Dechantsreiter, E. Planker, B. Mathä et al., "N-methylated cyclic RGD peptides as highly active and selective $\alpha(\mathrm{v}) \beta 3$ integrin antagonists," Journal of Medicinal Chemistry, vol. 42, no. 16, pp. 3033-3040, 1999.

[33] G. Huang, C. Zhang, S. Li et al., "A novel strategy for surface modification of superparamagnetic iron oxide nanoparticles for lung cancer imaging," Journal of Materials Chemistry, vol. 19, no. 35, pp. 6367-6372, 2009. 
[34] F. Xu, D. Lei, X. Du, C. Zhang, X. Xie, and D. Yin, "Modification of MR molecular imaging probes with cysteine-terminated peptides and their potential for in vivo tumour detection," Contrast Media and Molecular Imaging, vol. 6, no. 1, pp. 46-54, 2011.

[35] C. Y. Wu, Y. Pu, G. Liu et al., "MR imaging of human pancreatic cancer xenograft labeled with superparamagnetic iron oxide in nude mice," Contrast Media \& Molecular Imaging, vol. 7, no. 1, pp. 51-58, 2012.

[36] J. A. Frank, S. A. Anderson, H. Kalsih et al., "Methods for magnetically labeling stem and other cells for detection by in vivo magnetic resonance imaging," Cytotherapy, vol. 6, no. 6, pp. 621-625, 2004.

[37] S. Kobukai, R. Baheza, J. G. Cobb et al., "Magnetic nanoparticles for imaging dendritic cells," Magnetic Resonance in Medicine, vol. 63, no. 5, pp. 1383-1390, 2010.

[38] B. L. Strand, L. Ryan, P. In't Veld et al., "Poly-L-lysine induces fibrosis on alginate microcapsules via the induction of cytokines," Cell Transplantation, vol. 10, no. 3, pp. 263-275, 2001.

[39] D. L. J. Thorek and A. Tsourkas, "Size, charge and concentration dependent uptake of iron oxide particles by non-phagocytic cells," Biomaterials, vol. 29, no. 26, pp. 3583-3590, 2008.

[40] S. Boutry, S. Brunin, I. Mahieu, S. Laurent, L. Vander Elst, and R. N. Muller, "Magnetic labeling of non-phagocytic adherent cells with iron oxide nanoparticles: a comprehensive study," Contrast Media and Molecular Imaging, vol. 3, no. 6, pp. 223-232, 2008. 


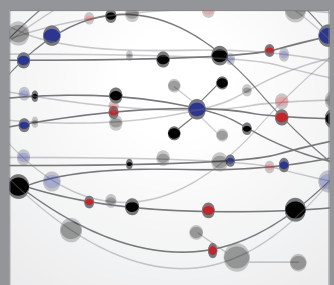

The Scientific World Journal
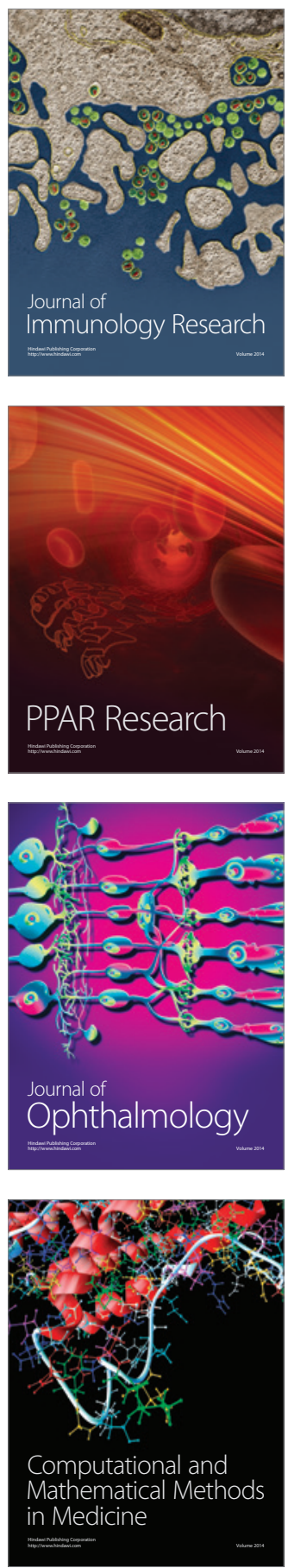

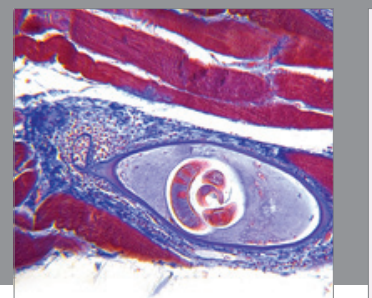

Gastroenterology

Research and Practice
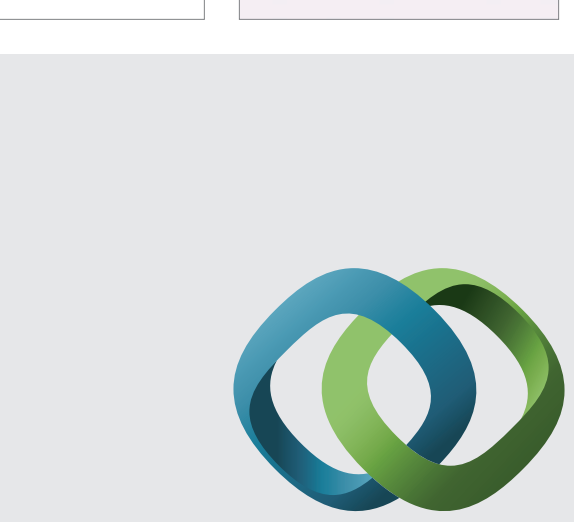

\section{Hindawi}

Submit your manuscripts at

http://www.hindawi.com
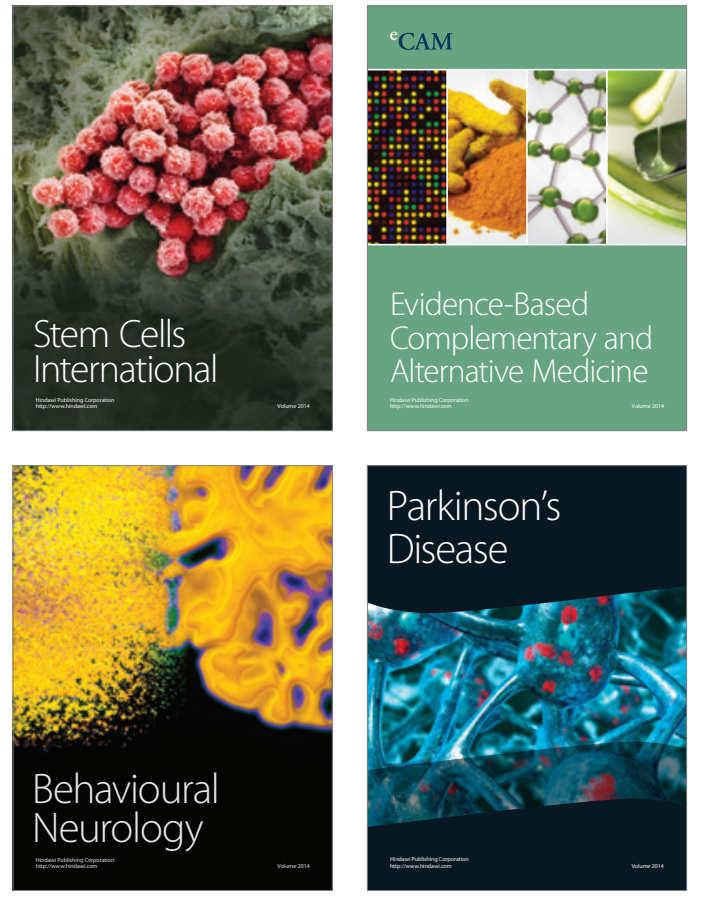
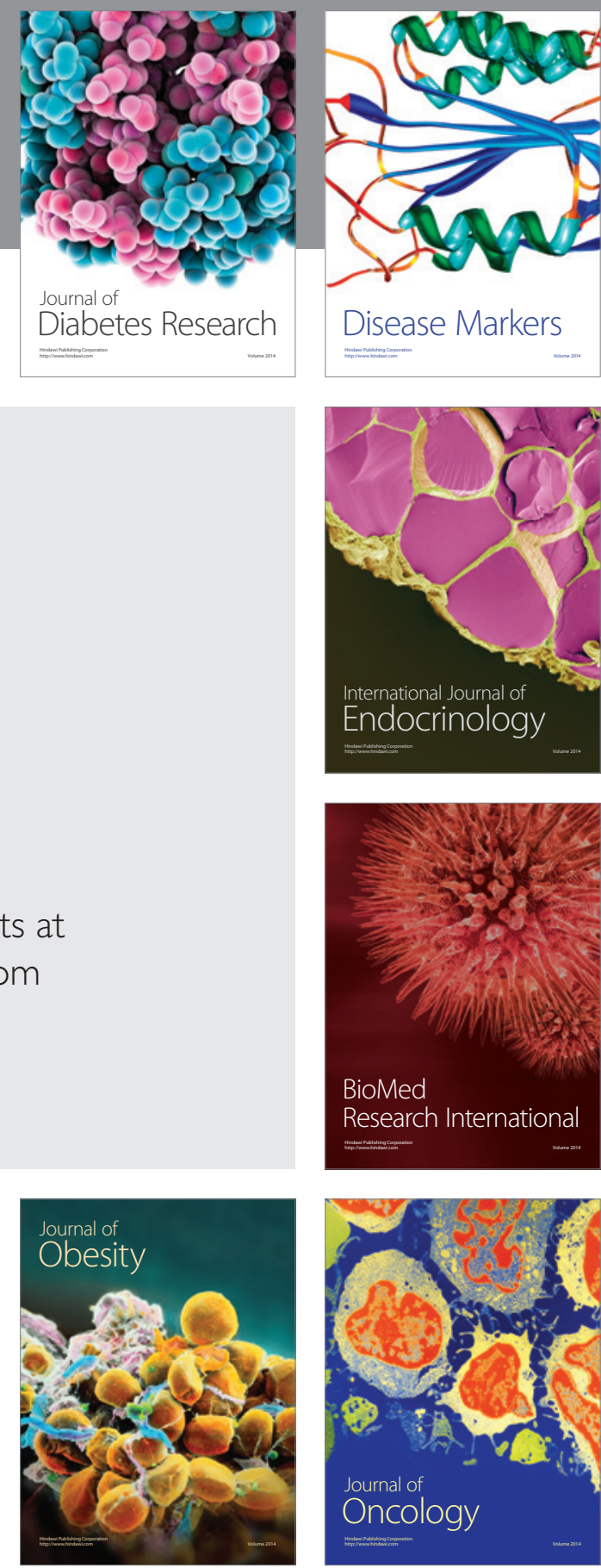

Disease Markers
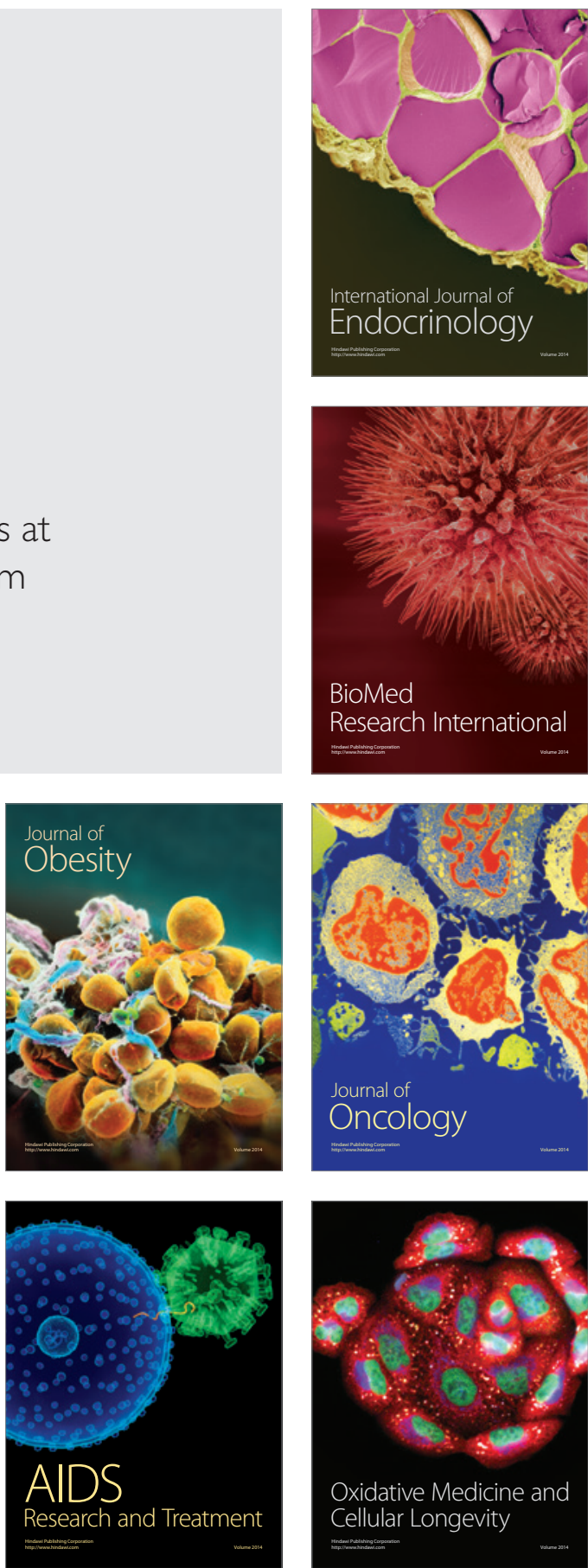